\title{
Monsters, fear and fun. Bringing creative methodologies into the higher education classroom to study children and childhood
}

\author{
Rosalina Pisco Costa ${ }^{1}$, Beatriz Roque ${ }^{2}$, Vanessa Carreira ${ }^{3}$ \\ ${ }^{1}$ Department of Sociology and CICS.NOVA, Universidade de Évora, Portugal, ${ }^{2}$ Faculdade \\ de Ciências Sociais e Humanas, NOVA FCSH, Portugal, ${ }^{3}$ Department of Sociology, \\ Universidade de Évora, Portugal.
}

\begin{abstract}
This paper addresses the methodology of Design Thinking and its applicability as a creative methodology when teaching and learning Sociology of Childhood in a higher education context. Students were asked to develop an exercise in order to expand and deepen the theoretical and conceptual knowledge discussed in theoretical classes. Active and creative methodologies were specifically and purposefully designed to develop the ability to think critically about the problems presented, stimulating debate and sociological imagination. Inspired by the Mindshake Design Thinking Model Evolution $6^{2}$, practical classes were organized and oriented towards specific techniques, namely the "Inspiration Board", "Intent Statement" and "Insight Clustering", following, respectively, the phases of exploration, data collection and analysis and interpretation of results. Illustration is given through the development of a research itinerary committed to think, discuss and creatively research the meanings of the "dark" and "darkness" of the night for children. Incorporating Design Thinking in the teaching and learning process in the field of social sciences, namely when researching children and childhood from a sociological perspective, proved to be a both fruitful and engaging tool both for teachers and students.
\end{abstract}

Keywords: Childhood; creative methods; darkness; design thinking; qualitative design; sociology. 


\section{Introduction}

There is a widespread consensus around the need and urgency to rethink curricula and teaching-learning methodologies in the context of higher education (UNESCO, 2016). Despite the greater use of information and communication technologies and a shift towards the digital (Twenge, 2017), characteristics distinguishing generations persist, leading individuals to think and learn differently (Töröcsik, Szücs, \& Kehl, 2014). Accordingly, after education is completed, when facing the labour market, young people are being increasingly questioned by employers regarding their transversal skills, namely the ability to think creatively and critically, to take initiative and to work collaboratively (Zemke, Raines \& Filipczak, 2013).

Having these assumptions as a backdrop, this paper presents and details the experience of using Design Thinking principles in the teaching and learning process in a higher-education context. The experience was developed within the framework of the "Sociology of Childhhood" course, during the academic year 2019/20. The reasons for developing such experience were twofold. On the one hand, because previous practice showed that one of the main challenges when teaching sociology of childhood to undergraduates is to break with common sense and overcome the epistemological barrier that impacts the ways how individuals who observe, namely students/young adults, perceive and conceptualize the individuals who are being observed, this is, children. On the other hand, because elective courses usually are more flexible, leaving the teacher with greater freedom to imagine creative teaching and learning solutions adjusted to specific challenges.

The main objective of "Sociology of Childhood" is to provide students with the theoretical, conceptual and methodological tools for a critical and sociologically anchored understanding of the diversity, relativity and complexity surrounding children and childhood in contemporary society. The course is structured in theoretical and practical classes, tutorial monitoring and remote solutions. Active and creative methodologies were specifically and purposefully designed to develop the ability to think critically about the problems presented, stimulating debate and sociological imagination. Inspired by Mindshake's Evolution \& Design Thinking $6^{2}$ model (Tschimmel, 2018), practical classes were organized and oriented towards specific phases and techniques, namely the "Inspiration Board", "Intent Statement" and "Insight Clustering". This paper presents and details the implementation of this particular pedagogical project, giving voice and turning the experience of the main actors involved teacher and students - more visible. Specifically, it contextualizes the proposed methodology and illustrates the pedagogical and research path adopted by a group of students committed to investigate meanings and representations around the dark of the night from the perspective of children (Roque and Carreira, 2020). The empirical exercise serves as a motto to discuss the place of Design Thinking and creative methodologies in motivating and engaging more 
effectively both students and teachers in the pedagogical relationship in a higher-education context and, ultimately, to think about its limits and challenges.

\section{Background}

Design Thinking refers to "a method and a process for investigating open and ill-defined problems, acquiring and analysing information, identifying opportunities for innovation, deepening empathy, experimenting with new perspectives and visualising new concepts" (Tschimmel et al., 2015, p. 6). In the Portuguese context, Katja Tschimmel has contributed strongly to give more visibility to such a methodology, insisting, in particular, on its transferability to several domains, namely education and training.

The theoretical and methodological foundations of Design Thinking are broad and diverse (Lawson, 1986; Rowe, 1987; Cross, Dorst, \& Roozenburg, 1992; Eastman, Mccracken, \& Newstetter, 2001). Design Thinking applies to the creative development of processes, strategies and programs, and is transversal to the collection of data, knowledge analysis, deepening of empathy, experimentation with new perspectives and ideas, visualization and prototyping of new concepts, always with a focus on results. Katja Tschimmel $(2015,2016$, 2018) argues that Design Thinking is an attitude (mindset), a model for structuring and focusing on a design process that can be used in education in the same way that it has been applied in product design processes and service systems.

The main argument for transferability into the field of education lies on the fact that Design Thinking is centered on the human being. Moreover, it is multidisciplinary and collaborative, optimistic and experimental (Tschimmel et al., 2015, p. 6). The transferability defended by Katja Tschimmel for the field of education is operationalized through the adaptation and application of the Mindshake Design Thinking Model Evolution $6^{2}$ model (Tschimmel, 2018), developed between 2012 and 2015, the year in which the last version was registered in Creative Commons sa-by (MINDSHAKE, 2020). This model can be used to guide a Design Thinking process applied in various areas; it includes quantitative and qualitative research methods, is based on primary and secondary data, and is connected with visual thinking and different tools for creating meaning. The model is called Evolution $6^{2}$, which the author explains in three moments. First, "Evolution", because the creative process is a process in permanent evolution, iterative and interactive, both at the level of people and situations. "E6", because the model is divided into six main phases, all of them starting with the letter E: "Emergence", "Empathy" "Experimentation", "Elaboration", "Exposition" and "Extension". Finally, "E6" " because in each phase of the process there are moments of "Exploration" (divergence) and "Evaluation" (convergence), thus, metaphorically raising the power of the model to the square. 
The last few years have witnessed the spread of an important set of methodologies considered innovative or creative in social research, including sociology (Denzin \& Lincoln, 2011; Kara, 2015; Mason \& Dale, 2011). These methodologies cover a diverse range of techniques and approaches resulting from the research experience in multi and interdisciplinary teams, and the need to answer the increasing complexity of social science research questions (Kara, 2015). Creative methodologies mean a wide range of methodologies, not necessarily new to the history of social research. The adjective stresses the procedural nature of the methodologies, emphasizing the creation of something from elements that already exist, arranging or articulating them in different combinations in order to solve specific questions or problems (Kara, 2015). Many of these methodologies are close to the principles and assumptions of Design Thinking, although not always in direct relation to this approach (Mäkelä et al., 2014). The following section explores in detail a teaching and learning exercise consisting in the application of some of the techniques of Design Thinking when studying children and childhood-related topics in the broader context of a Sociology undergraduate course. By the end, the authors expect to reflect critically on its scope, potential and limits in the higher-education context.

\section{Using Design Thinking to research children and childhood}

\subsection{Methodological approach}

This paper draws on the pedagogical work developed by the authors within the course "Sociology of Childhood" [SOC2425L], at the University of Evora. In the academic year 2019/20, students were asked to develop an empirical exercise consisting in a critical and grounded sociological reading of a specific theme or debate concerning children and childhood in contemporary society. A total of 17 small groups, of 2-3 students each, took part in that initiative. Each group of students had a different topic assigned, freely chosen among several broad topics suggested by the teacher. Inspired by the Mindshake Design Thinking Model Evolution $6^{2}$, the operationalization of the exercise encouraged the exploration of three specific phases: the "Inspiration Board", the "Intent Statement" and "Insight Clustering", following, respectively, the phases of exploration, data collection and analysis and interpretation of results. The next section illustrates the application of such techniques for the development of a research itinerary committed to think, discuss and creatively research the meanings of the "dark" and the "darkness" of the night for children (Roque and Carreira, 2020).

\subsection{Results}

Just as the Design Thinking techniques are developed with an open end, so this exercise started without knowing the point of arrival. The kick-off was given through the composition 
of an "Inspiration Board". An Inspiration Board is "a fun, risk-free and stressfree way to collect interesting images related to your project without analysing them. It is also an effective way to let go of critical and logical thoughts and to (re)discover parts of a larger picture that realistically illustrate the world of education and pedagogy." (Tschimmel et al., 2016, p. 31). Accordingly, students were asked to collect, as on a "pinboard", a set of elements (e.g. texts, images and artifacts), allowing them to think freely and creatively. Roque and Carreira brought into class nine inspiring elements, including a self-adhesive moon that glows in the dark, a pawn-shaped toy, a card game, a childhood poem and brushes. Each of these elements was presented orally before the class, and this narrative was later expanded through spontaneous interventions by other students in the room. The group took note of the contributions and after in-depth reflection chose to use the self-adhesive moon that glows in the dark as the main inspiring object. An articulated narrative embracing the various elements was the main methodological achievement of this phase. This narrative is always unique and spontaneous, as ideas succeed one another freely, prompted either by the presentation of the students who collected the elements or by the questions raised by other students in the classroom. While this exercise allowed students to perceive themselves as active actors in the teaching-learning process, it was crucial in linking them with the goals of the course, motivating and inspiring for further research steps.

In the broader framework of Mindshake Design Thinking Model Evolution 62, an "Intent Statement" is a convergent thinking tool, developed at the end of the Emergency phase. It is used to help finding the answer to the question "Why do we want to innovate?", and to guide subsequent phases. As Tschimmel puts it, "[m]ost of the time the decision to develop new content is based on a hunch, and feeling the necessity for change and improvement. [...] Sometimes however it is not easy to describe those early ideas in words and your concepts have to 'mature'. The elaboration of an Intent Statement helps you to clarify your determination for innovative content development." (Tschimmel et al., 2016, p. 77). Therefore, an Intent Statement reconciles intuition and assertiveness, as this should result in a clear statement of the purpose and development to follow. The invitation to define the research objectives through this alternative formulation brought added advantages to the research process. In order to provide a clear and concise answer, students were invited to write their intention by adapting the structure "What is [my] intention?" (Tschimmel, 2018, p. 25). Such a clarification allowed to guide further data collection procedures, namely the profile of children to be observed (e.g. age and social background), and recruitment steps (e.g. sampling process within a specific class and school). By way of example, the recruitment of 7 and 9-year-old children was done through a game, thus ensuring that all children were equally likely to join the study. Providing all children with the time for a game, served two main purposes. On the one hand, it brought researchers closer to children, overcoming the epistemological frontier raised by the age difference. On the other hand, the use of a game, including the clarification and acceptance of the rules, meant that children 
who were not part of the final sample did not feel resentful or excluded, perceiving that as a "natural" consequence of the rules of the game.

Additionally, the Intent Statement was determinant in preparing the research toolbox. The toolbox comprised three elements: the ethical commitment expressed in the "Informed Consent Statement", attached to the "Request for Authorization", the "Drawing Guide", and the "Interview Guide". The instruments used for data collection were drawings and interviews conducted with children. The drawings were asked first, in order to gain the children's trust, making them more relax with the researchers. The literature suggests that interviews with children should take place in familiar places, so that they feel as comfortable and safe as possible (Saramago, 2001). For this exercise, the school provided a room for such a purpose. The fact that this particular room was unknown to all the children interviewed made their reaction surprising. In the end, they were very excited because they got to know a new space, until then totally inaccessible to them. Given the age characteristics of the interviewees, the use of an everyday, and to a certain extent, familiar object, such as the smartphone to record the interview, also worked as a creative practice facilitating interaction in the context of social research (Costa, 2019).
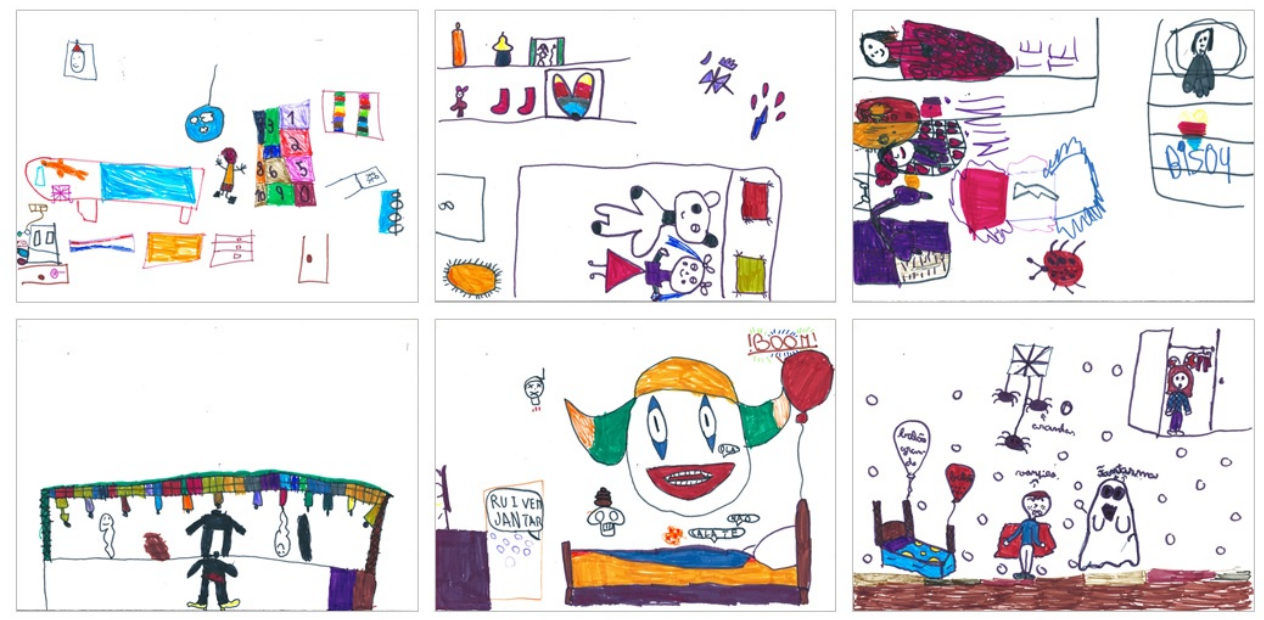

Figure 1. The dark in the children's gaze. Source: Children's drawings (2019).

As qualitative researchers seek a holistic and deep understanding of the topics under analysis (Denzin \& Lincoln, 2011), students were challenged to import from the Design Thinking model the "Insight Clustering" technique as a way to stimulate the qualitative analysis and interpretation phase. Insight Clustering is connected to brainwriting, "it helps to move from a divergent phase to a convergent phase by categorizing ideas and, at the same time, checking if the idea generation has been flexible (which means with ideas in several directions and thematic areas)." (Tschimmel et al., 2016, p. 85). Insight Clustering was key to understand 
what is behind the children drawing and, ultimately, to understand it (figure 1). Therein, students were asked to listen and look at the data from a more reflexive perspective, focusing their attention both in the textual and visual dimensions. Combining different elements and dimensions, Insight Clustering allowed to be attentive to the specificity of the children gaze over the dark of the night, and to overcome common sense and simplistic understandings opposing reality and fantasy. In fact, as Sarmento points out, in children's cultures, "the process of imagination of the real is foundational in the mode of intelligibility" (Sarmento, 2003, p. 16). Despite being frequently associated with negative feelings, such as fear, and scary figures - of which "monsters", "witches", "ghosts", "vampires", “zombies", "evil and murderers clowns", "pumpkins", "black holes", "skulls" or "spirits" were the most cited and visually depicted on the drawings - children also associate the dark of the night with "fun", "discovery", "curiosity" and "imagination". Moreover, data analysis unveils the presence of other beings, both human (namely, parents, grandparents and siblings), and non-human in the day/night transition, such as toys and peculiar objects (e.g. "a blanket", "a pillow", "a flashlight", the "television command", a "planet-shaped presence light", "a nightgown" or "stars and moons that glow in the dark". All these stimulate the children's imagination, presenting them with multiple colors, shapes, characters, sounds and various other sensory stimuli.

\section{Conclusions}

This paper explored the importance and value of incorporating Design Thinking in the teaching and learning process in the field of social sciences, namely when researching children and childhood from a sociological perspective. From the teacher perspective, Design Thinking allows to mobilize a set of tools granting to teach in a more plastic and intuitive way the social research methodologies, making them more attractive to students. From the students' perspective, the use of a different and new terminology seems to favor a positive and enthusiastic environment, refreshing the often barren field of social research methodology, thus making students more willing to engage in the learning process.

\section{Acknowledgments}

This work is financed by national funds through FCT - Foundation for Science and Technology, I.P., within the scope of the project «UIDB/04647/2020» of CICS.NOVA Centro Interdisciplinar de Ciências Sociais da Universidade Nova de Lisboa. 


\section{References}

Costa, R. (2019). iPhone, iResearch. Exploring the use of smart phones in the teaching and learning of visual qualitative methodologies. Journal of Visual Literacy, 38(1-2), 153 162. doi: 10.1080/1051144X.2019.1567073

Cross, N., Dorst, K., \& Roozenburg, N. (Eds.) (1992). Research in design thinking. Delft: Delft University Press.

Denzin, N., \& Lincoln, Y. (2011). The sage handbook of qualitative research. Thousand Oaks, CA: Sage.

Eastman, C., Mccracken, M., \& Newstetter, W. (Eds.) (2001). Design knowing and learning: cognition in design education. Oxford: Elsevier Science Ltd.

Kara, H. (2015). Creative research methods in the social sciences: a practical guide. Bristol: Policy Press.

Lawson, B. (1986). How designers think. London: The Architectural Press.

Mäkelä, M., Nimkulrat, N., \& Heikkinen, T. (2014). Editorial/Drawing as a research tool: making and understanding in art and design practice. Studies in Material Thinking, 11, 312. http://www.materialthinking.org/papers/147

Mason, J., \& Dale, A. (2011). Understanding social research: thinking creatively about method. London: Sage.

MINDSHAKE. (2020). Web page. https://www.mindshake.pt/ acessed June 28, 2020.

Roque, B., \& Carreira, V. (2020). Escuro: o que existe no espaço e no imaginário da criança. Transição entre o dia e a noite (Unpublished paper developped for the Sociology of the Family Course). Universidade de Évora, Portugal.

Rowe, P. (1987). Design thinking. Cambridge, Mass: M.I.T. Press.

Saramago, S. S. (2001). Metodologias de pesquisa empírica com crianças. Problemas $e$ Práticas, 9-29.

Sarmento, M. (2003). As culturas da infância nas encruzilhadas da segunda modernidade. Em M. Sarmento, \& A. Cerisara (Orgs.), Crianças e miúdos, perspetivas sociopedagógicas da infância e educação (pp. 9-34). Porto: ASA.

Törócsik, M., Szúcs, K., \& Kehl, D. (2014). How generations think: research on generation Z. Communicatio, 1, 23-45. http://www.acta.sapientia.ro/acta-comm/comm1.htm

Tschimmel, K. (2018). Toolkit Evolution 62. An E-handbook for practical Design Thinking for Innovation. Porto: MINDSHAKE.

Tschimmel, K., Loyens, D., Soares, J., \& Oraviita, T. (2016). D-Think Toolkit. Design Thinking applied to education and training. Matosinhos: Ed. ESAD.

Tschimmel, K., Santos, J., Loyens, D., Jacinto, A., Monteiro, R., \& Valença, M. (2015). Research Report D-Think: Design Thinking applied to education and training. Matosinhos: ESAD.

Twenge, J. (2017). iGen. New York: Atria Books.

UNESCO. (2016). Repensar a educação. Brasília: Edições UNESCO.

Zemke, R., Raines, C., \& Filipczak, B. (2013). Generations at work: managing the clash of Boomers, Gen Xers, and Gen Yers in workplace. New York: AMACOM. 